\title{
Advances in spinal cord protection for complex aortic repairs
}

\author{
Lisa S. Foley, MD, MSCS, and T. Brett Reece, MD
}

\footnotetext{
From the Thoracic Aortic Program, Division of Cardiothoracic Surgery, Department of Surgery, School of Medicine, University of Colorado, Aurora, Colo.

Funding for this work was provided by the Department of Surgery, School of Medicine, University of Colorado. Disclosers: Authors have nothing to disclose with regard to commercial support.

Received for publication Sept 4, 2015; accepted for publication Sept 8, 2015; available ahead of print Dec 11, 2015 .

Address for reprints: Lisa S. Foley, MD, MSCS, 12631 E 17th Ave, C302, Aurora, CO 80045 (E-mail: lisa.foley@ ucdenver.edu).

J Thorac Cardiovasc Surg 2016;151:614-5

$0022-5223 / \$ 36.00$

Copyright (c) 2016 by The American Association for Thoracic Surgery

http://dx.doi.org/10.1016/j.jtcvs.2015.09.137
}

Spinal cord ischemia (SCI) and subsequent paraplegia remains the most dreaded obstacle for complex thoracoabdominal aortic interventions, occurring in up to $20 \%$ of patients undergoing extent II repair. Although aneurysm extent, location, presence of dissection, and urgency confer risk, SCI still occurs in roughly $4 \%$ of elective nondissected short- segment aortic repairs. ${ }^{1,2}$ This relatively high incidence in low-risk patients underscores the humbling and indiscriminate nature of postoperative paraplegia.

The contemporary approach to spinal cord protection is based on optimizing spinal cord hemodynamics through cerebrospinal fluid drainage, permissive hypertension, and preservation of cord perfusion vessels. Perfusion support will remain a mainstay of treatment for high-risk procedures and for patients exhibiting spinal cord deficits; however, the metabolic tolerance of the cord remains at odds with the recovery of blood flow through the collateral network. Emerging frontiers are focusing on expanding the spinal cord's ability to tolerate ischemia and, more importantly, optimizing perfusion techniques, enhancing recovery of the cord, and maximizing the dynamic nature of the collateral arterial network. ${ }^{3,4}$

\section{EXPANDING ISCHEMIC TOLERANCE}

The focus of most spinal cord injury translational research is on identifying methods to increase the spinal cord's tolerance of transient ischemia. Although there have been many operative advances in reducing the overall surgical ischemic insult, it has not been eliminated. Spinal cord ischemiareperfusion injury results in a bimodal pattern of neurologic injury thought to be due to an initial ischemic insult that activates a secondary inflammatory insult during reperfusion. ${ }^{5}$ An ongoing question in ischemia tolerance research is how to preserve injured yet viable neurons during the secondary reperfusion insult and subsequent loss by apoptosis.

Erythropoietin (EPO) holds significant promise among pharmacologic treatments, with established antiinflammatory and neuroprotective effects in murine models of ischemic stroke and contusive spinal cord injury. ${ }^{6}$ EPO

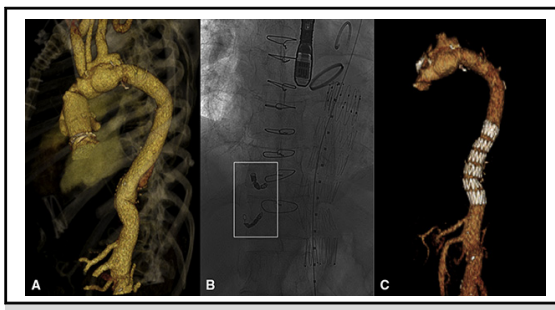

A patient with Marfan's syndrome presenting with an expanding intercostal patch aneurysm. His initial operation was complicated by postprocedural weakness, which recovered. He had 4 large intercostals coming off the patch, all of which would be taken with thoracic endovascular aortic repair (TEVAR) coverage of the patch (A). Therefore, we coiled 2 of the intercostals (B) at 2 weeks before TEVAR, which excluded the others (C). The patient exhibited no weakness or signs of spinal cord injury, demonstrating the feasibility of this approach.

\section{Central Message}

Advances in spinal cord protection are working to expand ischemia tolerance, optimize perfusion, and maximize the collateral network.

See Articles page 509 in the February issue and 675 in the September issue.

has been proven to improve functional outcomes and reduce neuronal loss in multiple animal models of ischemic injury, including in our own laboratory's murine model of spinal cord ischemia-reperfusion injury using a thoracic aortic cross-clamp. $^{6-9}$ The mechanism of EPO in ischemiareperfusion injury relies on a specific tissue protective receptor that is unique from the hematopoietic receptor ${ }^{8,9}$ in that it activates antiapoptotic pathways and is thought to preserve neurons throughout the reperfusion phase of injury.

Another important focus of ischemia-reperfusion injury research is in on dampening the severity of the reperfusion insult. Microglia play a significant role in enhancing the inflammatory signaling that follows neurologic ischemia. Inhibitors of microglial activation, such as alpha 2 receptor agonists and Toll-like receptor 4 receptor antagonists, have promising data from animal models that support their efficacy in improving functional and cellular outcomes. ${ }^{10-12}$

Although these agents have shown promising results, it is unlikely that multi-institutional randomized trials will be supported by the pharmacologic industry. Nonetheless, the importance of these adjuncts cannot be overemphasized, given that emergent cases may be limited to these treatments alone. 


\section{PRECOLLATERALIZATION}

For many years, Griepp and colleagues ${ }^{4,13,14}$ have focused on characterizing changes in blood supply to the spinal cord occurring after different types of aortic repair. They measured spinal cord perfusion pressure (SCPP) following sacrifice of intercostal and lumbar arteries in a porcine model of SCI and demonstrated a 24- to 48-hour reduction in SCPP following sacrifice of all intercostal and lumbar arteries, analogous to the injury induced by thoracoabdominal aneurysm repair. Remarkably, SCPP returned to normal levels by 48 hours despite no intercostal or lumbar artery reimplantation, suggesting augmentation of existing collateral arterial vasculature acutely by arteriogenesis. That study and similar efforts have advanced our understanding of the dynamic nature of spinal cord blood supply and the ability to manipulate and augment cord perfusion.

Consequently, manipulation of the collateral network as a means of arteriogenic preconditioning has progressed in animal models, and is now being used in clinical practice as means of preventing SCI during high-risk procedures. Surgeons have begun temporally spreading out the sacrifice of direct spinal cord inflow sacrifice by staging full aortic exclusion through both open and hybrid techniques ${ }^{4,13,14}$; for instance, the proximal to mid-descending can be stented before the eventual open completion. Another approach has been the creation of graft fenestrations to intentionally perfuse the aneurysm sac, with coverage of the fenestration done at a later date.

The anatomy of the aneurysm dictates the extent of staging, however. The real future of staging collateralization focuses on the intercostal and lumbar arteries rather than on the aneurysm. The segmental feeders can be occluded directly with consistent control of the extent of sacrifice with serial embolization of intercostal or lumbar arteries. In fact, the first-in-man experience of segmental arterial coil embolization to prevent spinal cord was published in the Journal earlier this year. ${ }^{15-17}$ This preemptive sacrifice of spinal cord blood flow in a region that inevitably will be sacrificed for the aneurysm repair allows for distribution of the overall ischemic insult over time and for augmentation of the arterial collateral network before additional loss of segmental arteries.

Surgeons at our institution also have performed this procedure before repair of an extent II aneurysm. This technique has proven safe to date, but the need for research remains in terms of how to occlude these vessels, how many vessels to take at a time, how long to wait between sacrifices to allow perfusion recovery, and how to decide which collaterals to take first.

\section{SUMMARY}

In summary, paraplegia following complex aortic surgery remains a devastating complication that has been improved on in past decades but seems to have hit a ceiling in terms of the inability to further reduce its occurrence. Current advances in collateral network manipulation and ischemia tolerance adjuncts hold significant promise in finally affecting improvement in patient outcomes and reduction of this postoperative complication. Further research on spinal cord ischemia injury is warranted to examine the potential benefits and limitations of these approaches.

\section{References}

1. Coselli JS, LeMaire SA, Conklin LD, Köksoy C, Schmittling ZC. Morbidity and mortality after extent II thoracoabdominal aortic aneurysm repair. Ann Thorac Surg. 2002;73:1107-15.

2. Conrad MF, Crawford RS, Davison JK, Cambria RP. Thoracoabdominal aneurysm repair: a 20-year perspective. Ann Thorac Surg. 2007;83:S856-61.

3. Coselli JS, LeMaire SA, Köksoy C, Schmittling ZC, Curling PE. Cerebrospinal fluid drainage reduces paraplegia after thoracoabdominal aortic aneurysm repair: results of a randomized clinical trial. J Vasc Surg. 2002;35:631-9.

4. Geisbüsch S, Stefanovic A, Koruth JS, Lin HM, Morgello S, Weisz DJ, et al. Endovascular coil embolization of segmental arteries prevents paraplegia after subsequent thoracoabdominal aneurysm repair: an experimental model. $J$ Thorac Cardiovasc Surg. 2014;147:220-6.

5. Smith PD, Puskas F, Meng X, Cho D, Cleveland JC Jr, Weyant MJ, et al. Ischemic dose-response in the spinal cord: both immediate and delayed paraplegia. J Surg Res. 2012;174:238-44.

6. Brines M, Cerami A. Erythropoietin-mediated tissue protection: reducing collateral damage from the primary injury response. J Intern Med. 2008;264: 405-32.

7. Leist M, Ghezzi P, Grasso G, Bianchi R, Villa P, Fratelli M, et al. Derivatives of erythropoietin that are tissue protective but not erythropoietic. Science. 2004 305:239-42.

8. Smith PD, Puskas F, Fullerton DA, Meng X, Cho D, Cleveland JC, et al. Attenuation of spinal cord ischemia and reperfusion injury by erythropoietin. J Thorac Cardiovasc Surg. 2011;141:256-60.

9. Foley LS, Fullerton DA, Bennett DT, Freeman KA, Mares J, Bell MT, et al. Spinal cord ischemia reperfusion injury induces erythropoietin receptor expression. Ann Thorac Surg. 2015;100:41-6.

10. Bell MT, Puskas F, Agoston VA, Cleveland JC Jr, Freeman KA, Gamboni F, et al Toll-like receptor 4-dependent microglial activation mediates spinal cord ischemia-reperfusion injury. Circulation. 2013;128(11 Suppl 1):S152-6.

11. Bell MT, Puskas F, Bennett DT, Herson PS, Quillinan N, Fullerton DA, et al. Dexmedetomidine, an $\alpha-2 \mathrm{a}$ adrenergic agonist, promotes ischemic tolerance in a murine model of spinal cord ischemia-reperfusion. J Thorac Cardiovasc Surg. 2014; 147:500-6.

12. Bell MT, Agoston VA, Freeman KA, Puskas F, Herson PS, Mares J, et al. Interruption of spinal cord microglial signaling by alpha-2 agonist Dexmedetomidine in a murine model of delayed paraplegia. J Vasc Surg. 2014;59:1090-7.

13. Etz CD, Kari FA, Mueller CS, Brenner RM, Lin HM, Griepp RB. The collateral network concept: remodeling of the arterial collateral network after experimental segmental artery sacrifice. J Thorac Cardiovasc Surg. 2011;141: 1029-36.

14. Etz CD, Zoli S, Mueller CS, Bodian CA, Di Luozzo G, Lazala R, et al. Staged repair significantly reduces paraplegia rate after extensive thoracoabdominal aortic aneurysm repair. J Thorac Cardiovasc Surg. 2010; 139:1464-72.

15. Luehr M, Salameh A, Haunschild J, Hoyer A, Girrbach FF, von Aspern K, et al Minimally invasive segmental artery coil embolization for preconditioning of the spinal cord collateral network before one-stage descending and thoracoabdominal aneurysm repair. Innovations (Phila). 2014;9:60-5.

16. Etz CD, Debus ES, Mohr FW, Kölbel T. First-in-man endovascular preconditioning of the paraspinal collateral network by segmental artery coil embolization to prevent ischemic spinal cord injury. J Thorac Cardiovasc Surg. 2015;149:1074-9.

17. Williams GM, Roseborough GS, Webb TH, Perler BA, Krosnick T. Preoperative selective intercostal angiography in patients undergoing thoracoabdominal aneurysm repair. J Vasc Surg. 2004;39:314-21. 